Rev. Interd. em Cult. e Soc. (RICS), São Luís, v. 7, n. 2, p. 191- 206, jul./dez. 2021

ISSN eletrônico: $2447-6498$

\title{
Acessibilidade cultural no Museu do Doce da Universidade Federal de Pelotas: a trajetória de uma proposta sensorial ${ }^{1}$
}

\section{Cultural accessibility at the Doce Museum of the Federal University of Pelotas: the trajectory of a sensorial proposal}

DESIRÉE NOBRE SALASAR

Doutoranda do Programa de Pós-Graduação em Memória Social e Patrimônio Cultural da Universidade Federal de Pelotas. Bolsista CAPES. Doutoranda em Museologia pela Universidade Lusófona de Humanidades e Tecnologias/Portugal. dnobre.to@gmail.com

FRANCISCA FERREIRA MICHELON Docente do Programa de Pós-Graduação em Memória Social e Patrimônio Cultural da Universidade Federal de Pelotas. fmichelon.ufpel@gmail.com

\section{RESUMO}

Entendida como um direito de todas as pessoas, a Acessibilidade Cultural caracteriza-se como um movimento que busca a igualdade cultural e, consequentemente, a social. Ao admitirem-se as diferenças, o caminho a ser traçado busca o diálogo entre realidade e utopia, e a consolidação de práticas, recursos e alternativas que promovem valores coletivos e que acabam promulgando a existência de espaços inclusivos, que proporcionam o convívio entre os diferentes e que apresentam a diferença como instância de aprendizado conjunto. Com tal entendimento, o texto relata a trajetória de uma proposta sensorial desenvolvida em um programa de extensão universitária no Museu do Doce da Universidade Federal de Pelotas e seus desdobramentos intra e extramuros da universidade. Os resultados apontam para um espaço que se tornou referência na cidade, não só pelos seus recursos propriamente ditos, mas pelos métodos que foram utilizados para que estes fossem implementados e obtivessem êxito.

Palavras-chave: Acessibilidade Cultural. Museu. Doce.

\begin{abstract}
Understood as a right of all people, a cultural accessibility, a movement that seeks a cultural equality and, consequently, a social. To admit as differences, the path to the path and the search between reality and utopia, and the consolidation of practices, resources and alternatives that promote collective values and that end up promulgating a hypothesis of inclusive spaces, that promote the conviviality between the different and which has a relation as learning of conjunto. Con the understanding, the text reports a trajectory of a sensorial proposal, in a program of university extension, the Museum of the Federal University of
\end{abstract}

\footnotetext{
${ }^{1}$ Artigo submetido para avaliação em 25 de setembro de 2021 e aprovado em 12 de novembro em 2021.
} 
Rev. Interd. em Cult. e Soc. (RICS), São Luís, v. 7, n. 2, p. 191- 206, jul./dez. 2021

ISSN eletrônico: $2447-6498$

Pelotas and its unfolding intra and extra walls of the university. The results are pointed to a space that refers to the city, not only by its own resources, but also by the methods that were used for them to be implemented and validated.

Keywords: Cultural Accessibility. Museum. Sweet.

\section{INTRODUÇÃO}

A temática da inclusão da pessoa com deficiência na área da cultura encontra-se em ascensão nas últimas décadas. Como um paradigma emergente da sociedade, que busca transformar a herança de um passado que produziu desigualdades sociais e culturais frente aos diferentes, distintas redes se articulam através de diferentes atores para que se desconstruam as barreiras impostas por séculos de exclusões culturais e sociais para este segmento da população.

Entendida como um direito emergente das minorias, a acessibilidade cultural para pessoas com deficiência caracteriza-se como um movimento contra-hegemônico da desigualdade social e cultural. Admitindo as diferenças e em busca de um diálogo entre realidade e utopia, a área se consolida através de enfrentamentos de valores coletivos que perpassam gerações desencadeando um papel preponderante de que a pessoa com deficiência é que deve se adequar aos espaços e não o contrário.

O sociólogo Boaventura de Souza Santos, ao propor uma transição paradigmática da sociedade, aponta que

\footnotetext{
Uma globalização alternativa, contra-hegemônica, constituída pelo conjunto de iniciativas, movimentos e organizações que por intermédios de vínculos, redes e alianças globais/locais, lutam contra a globalização neoliberal mobilizados pelo desejo de um mundo melhor, mais justo e mais pacífico que julgam possível e a quem sentem ter direito (SANTOS, 2002, p. 15).
}

Em uma das suas mais célebres frases, o autor argumenta que "[...] temos o direito de ser iguais quando a nossa diferença nos inferioriza; e temos o direito de ser diferentes quando a nossa igualdade nos descaracteriza" (SANTOS, 2003, p. 56). Em consonância com Santos, Bauman (1999, p. 249) também assinala a relevância do convívio entre diferentes: “[...] ser diferente é o que nos faz semelhantes uns aos outros e que eu só posso respeitar a minha própria diferença respeitando a diferença do outro".

Assim entendidas, as questões ligadas às deficiências demandam que se tenha olhar cuidadoso para o contexto no qual elas estão inseridas e que se busque aprender com as 
Rev. Interd. em Cult. e Soc. (RICS), São Luís, v. 7, n. 2, p. 191- 206, jul./dez. 2021

ISSN eletrônico: $2447-6498$

vivências e potencialidades que pautam a vida das pessoas com deficiência. Espera-se que este seja um dos caminhos para uma sociedade com mais igualdade de oportunidades.

Assim, refletir sobre as diferenças no campo das deficiências, cumpre a função de gerar possibilidade de que se reconheça que parte das atitudes que acabam invisibilizando a existência das pessoas com deficiência advém de estereótipos que atuam de modo imanente há muito tempo. Portanto, é possível dizer que o conceito de acessibilidade cultural não diz respeito a uma ou outra ação isolada, como se pode exemplificar pela ideia de direito garantido através de isenção de pagamentos ou pela prática de valores acessíveis aos ingressos em eventos e espaços culturais. Qualquer ação colabora, mas não assegura que o caminho tomado seja acessível. Segundo Dorneles e Júnior (2014, p. 107), para que a acessibilidade cultural seja efetiva é "[...] necessário pensar o direito cultural de fruir com a produção estética, artística e cultural". Há, no bojo desta afirmação, o entendimento de que o direito cultural só pode ser exercido se à pessoa com deficiência é dada a condição de fruição, participação, produção e expressão pessoa com deficiência no ambiente cultural. Tal compreensão suplanta a ideia de que ingressar é incluir. Não basta entrar ou estar presente. Só isso não faz com que a pessoa esteja incluída de fato. A complexidade do fato é que para incluir há de se criar estratégias de acessibilidade, que oportunizem a fruição para os mais diversos públicos, incluindo pessoas com deficiência.

\section{AS DIMENSÕES DA ACESSIBILIDADE}

O preâmbulo acima ajuda a compreender por que tornar um museu inclusivo é meta desafiadora. Falar em acessibilidade não é pensar somente em pessoas com deficiência, o conceito de condição de acesso vai muito além. Empregando uma definição simples, tornar acessível é promover iguais condições para que o maior número possível de pessoas diversas entre si, com ou sem deficiência, possam fruir juntas de um evento ou de um espaço cultural. Assim, para além das pessoas com deficiências sensoriais, físicas/motoras ou intelectuais, a acessibilidade também oferece oportunidades para crianças, idosos, pessoas com limitações temporárias, entre outras. Para tal, é necessário que o espaço contemple as seis dimensões da acessibilidade identificadas por Romeu Sassaki (2009): atitudinal, metodológica, programática, arquitetônica, comunicacional e instrumental. E assim, apresenta-se possível constituir um programa que se balize pelo conceito de Desenho Universal ${ }^{2}$.

\footnotetext{
${ }^{2}$ Produtos gerados sobre o conceito de desenho universal devem incluir o maior número possível de pessoas de maneira a expressar que a diversidade é uma condição inerente à humanidade. O Desenho Universal possui sete princípios básicos: Uso equitativo, uso flexível, uso simples e intuitivo, informação de fácil percepção, tolerância ao erro, esforço físico mínimo e o dimensionamento de espaços para acessos e usos abrangentes. (GOVERNO DO ESTADO DE SÂO PAULO, 2017)
} 
Rev. Interd. em Cult. e Soc. (RICS), São Luís, v. 7, n. 2, p. 191- 206, jul./dez. 2021

\subsection{A acessibilidade atitudinal}

Destas, a acessibilidade atitudinal talvez seja a mais difícil de ser trabalhada, porque implica que o sujeito irá se deparar com sentidos e conceitos pré-concebidos. Como o nome sugere, atitudinal pode ser traduzido como "as minhas atitudes frente à pessoa". No caso das pessoas com deficiência ainda há (embora em menor proporção) um pré-julgamento em relação às potencialidades destas. Um museu pode estar totalmente acessível, mas se houver um funcionário que não esteja preparado para receber uma pessoa com deficiência, é possível que o visitante deixe de viver a plenitude de uma experiência positiva. O preparo de toda a equipe que entra ou pode entrar em contato com o público é o meio mais eficaz para obter resultados desejáveis. Uma equipe sensibilizada, que conheça as deficiências e limitações, saberá lidar com diferentes públicos e saberá orientar e maximizar o uso dos recursos disponíveis. Assim, entendendo que a pessoa deve vir à frente da sua deficiência, como a própria nomenclatura diz, um funcionário capacitado auxiliará o visitante da melhor forma

possível, gerando para o museu uma qualidade essencial: a receptividade. No entanto, como já dito, há públicos que demandam um mediador preparado. Apenas para lembrar dois dos mais frequentes: crianças e idosos. Um funcionário que não esteja preparado pode diminuir ou, até mesmo, anular a experiência que o visitante destas categorias viria a ter. Em outras palavras, o desconhecimento pode causar o afastamento. Exemplo: ao ignorar que o visitante poderia fazer uso de determinado recurso, o mediador pode causar o empobrecimento ou total comprometimento da aproximação da pessoa com outros visitantes e com o próprio museu. Outro exemplo: quando o visitante pertence a uma faixa etária de até 12 anos é necessário adaptar o discurso, mas não se deve perder o critério da explicação. E, ainda, no caso dos idosos, deve haver a consciência de que nem todo idoso apresenta necessidades especiais. $\mathrm{O}$ mediador precisa observar a pessoa e evitar situações muito frequentes como a de pressupor que a pessoa, em decorrência da idade, necessita de que falem alto e pausadamente com ela. Estes são exemplos de atitude que se forem embasadas em não pré-julgar o visitante resultam em um procedimento simples e eficaz: falar com o visitante primeiro e perceber/perguntar se é necessário algum recurso assistivo.

\subsection{A acessibilidade metodológica e a instrumental}


Rev. Interd. em Cult. e Soc. (RICS), São Luís, v. 7, n. 2, p. 191- 206, jul./dez. 2021

As duas estão intimamente ligadas, pois enquanto a primeira propõe métodos para efetivar a condição de acesso, a segunda aponta os instrumentos e meios que serão utilizados para que os métodos sejam efetivados. Por exemplo, se o museu quer tornar uma fotografia acessível a uma pessoa com deficiência visual, o método utilizado será um audioguia, enquanto o instrumento para efetivação do entendimento da obra será a audiodescrição daquela imagem, aliada a um recurso tátil.

\subsection{A acessibilidade programática}

A acessibilidade programática diz respeito à legislação e às normativas, ou seja, será através dela que a pessoa com deficiência poderá buscar o cumprimento de seus direitos como cidadão.

Com o advento das discussões acerca da temática de inclusão da pessoa com deficiência, inúmeras leis surgem no Brasil e no exterior para amparar esta parcela da população e equipará-las com as demais pessoas.

Em vigência no Brasil, atualmente, há mais de 30 leis e decretos ligados à temática, entretanto ressalta-se aqui o Estatuto da Pessoa com Deficiência - Lei Brasileira de Inclusão, Lei 13.146, de 6 de julho de 2015. Esta foi uma construção coletiva do próprio público-alvo, em resposta à Convenção dos Direitos da Pessoa com deficiência, da ONU, no qual o Brasil é um país signatário.

Em todos estes textos observamos a importância de garantir os direitos básicos às pessoas com deficiência, para que elas possam viver em condições de igualdade de oportunidades com os demais. Desta forma, as responsabilidades para que a pessoa possa circular livremente, recaem sobre a sociedade que não está preparada para recebê-lo. Isso quer dizer que a pessoa tem deficiência, mas é a sociedade que impede que ela tenha autonomia e seja independente.

\subsection{A acessibilidade arquitetônica}

A acessibilidade arquitetônica é caracterizada pela eliminação de barreiras físicas em ambientes, edifícios, equipamentos urbanos etc. Para tal, no Brasil há uma normativa ${ }^{3}$ que 
Rev. Interd. em Cult. e Soc. (RICS), São Luís, v. 7, n. 2, p. 191- 206, jul./dez. 2021

ISSN eletrônico: 2447-6498

regulamenta e dá os parâmetros necessários para que os ambientes estejam aptos a receberem públicos diversos. Assim, pode-se dizer que é pela acessibilidade arquitetônica que se facilita a independência na locomoção de todos. Por trazer mudanças estruturais (como rampas, elevadores e banheiros acessíveis) esta é a principal dimensão de acessibilidade visualizada pela população em geral e, na maioria das vezes, pó desconhecimento de todas as dimensões, é considerada como a única forma de acessibilizar um espaço.

Desta forma, faz-se necessário fazer um diagnóstico do ambiente, levantando suas barreiras arquitetônicas de modo a buscar solucioná-las para que se possa atender um maior número de pessoas possível.

\subsection{A acessibilidade comunicacional}

A acessibilidade comunicacional é a garantia que não haverá barreiras de comunicação entre os indivíduos ou entre ambiente e indivíduo, por exemplo.

No caso de pessoas Surdas, nativas da Língua Brasileira de Sinais, a compreensão de uma exposição muito carregada de textos poderá caracterizar uma barreira comunicacional, uma vez que os textos escritos em língua portuguesa não estão acessíveis para o nativo da Libras. Assim, através de um videoguia ou um tradutor/intérprete esta barreira comunicacional poderá ser solucionada. Para uma pessoa cega, uma exposição cheia de pinturas, essencialmente visual, e que não possua recursos como audiodescrição e experiências táteis, também não haverá comunicação e o visitante sairá sem entender o conteúdo ali exposto.

Assim, unindo estas seis dimensões chega-se à inclusão. Mas é importante ressaltar que houve um entendido, no caso que aqui se analisa, que para a inclusão ser efetiva, o desenho universal deveria ser levado em conta no projeto de todos os produtos desenvolvidos pelo Programa "Museu do Conhecimento para Todos".

\section{PROGRAMA DE EXTENSÃO: MUSEU DO CONHECIMENTO PARA TODOS (MCT)}


Rev. Interd. em Cult. e Soc. (RICS), São Luís, v. 7, n. 2, p. 191- 206, jul./dez. 2021

ISSN eletrônico: $2447-6498$

"O Museu do Conhecimento para Todos: inclusão cultural para pessoas com deficiência" foi um programa de extensão universitária ${ }^{4}$ da Universidade Federal de Pelotas, lotado no Instituto de Ciências Humanas, no Departamento de Museologia, Conservação e Restauro, e esteve ativo de 2012 a 2016. Seu principal objetivo era contribuir para a formação de profissionais aptos a entender, promulgar e exercer seu papel social em prol da inclusão e acessibilidade cultural das pessoas com deficiência em museus, através da ação interdisciplinar e fundado pelo princípio da indissociabilidade entre ensino, pesquisa e extensão.

Os museus aos quais se referia o Programa eram aqueles implantados na Universidade Federal de Pelotas. Utilizou-se em seus produtos os princípios do Desenho Universal, embora em alguns, apenas alguns dos princípios. No entanto, o conceito geral esteve presente como norteador para sintonizar a pluralidade da equipe, que contava com recursos humanos e materiais de sete cursos de bacharelado ${ }^{5}$ e de dois programas de pós-graduação ${ }^{6}$. Havia o desafio de fazer com que as áreas articuladas conversassem entre si, de forma a perceberem como poderiam confluir os conhecimentos que constroem situações inclusivas. Dos sete princípios, o mais importante foi a tolerância ao erro.

Durante todo o período de desenvolvimento, o Programa contou com instituições parceiras que atendem públicos com deficiência na cidade de Pelotas: a Escola de Educação Especial e o Centro de Reabilitação Visual Louis Braille. Estes parceiros auxiliaram tanto na proposição de metodologias, quanto na avaliação dos resultados obtidos do programa. Em um determinado momento, disponibilizaram os meios para a confecção de alguns produtos.

Durante os dois primeiros anos, a equipe do Programa capacitou-se para o desenvolvimento de recursos de tecnologia assitiva e para a compreensão intrínseca do campo cultural inclusivo. Foram feitas visitas técnicas, organizados eventos e oficinas.

O primeiro resultado de todo o investimento ocorreu, efetivamente, em 2014 com a implantação do Memorial do Anglo. O lugar conta a trajetória do extinto frigorífico Anglo (atual Campus Porto da Universidade) desde a sua fundação até o momento em que o prédio passa a ser da UFPel. Este ambiente recebeu recursos assistivos ${ }^{7}$ voltados, principalmente, para público com deficiência visual, haja vista que residia na elaboração de uma proposta

\footnotetext{
${ }^{4} \mathrm{O}$ programa foi contemplado com recursos em dois editais Proext-MEC (2012 e 2015).

${ }^{5}$ Arquitetura e Urbanismo, Museologia, Conservação e Restauro, Terapia Ocupacional, Cinema, Design Gráfico e Design Digital.

${ }^{6}$ de Arquitetura e Urbanismo e de Memória Social e Patrimônio Cultural.

${ }^{7}$ Legendas em braile, audiodescrição de fotografias, maquetes e esquemas táteis, cores contrastantes, iluminação direcionada e mobiliário ergonômico.
} 
Rev. Interd. em Cult. e Soc. (RICS), São Luís, v. 7, n. 2, p. 191- 206, jul./dez. 2021

ISSN eletrônico: $2447-6498$

inclusiva preferencialmente voltada para este público. $\mathrm{O}$ grande desafio, neste caso, foi o trabalho com a acessibilidade comunicacional ${ }^{8}$, porque a exposição era, praticamente, visual. Todas as imagens expostas eram fotográficas, e o desafio a ser vencido era, justamente, garantir que pessoas com deficiência visual tivessem igualdade de oportunidades para conhecer e fruir o conteúdo da exposição como os demais. A sistemática empregada optou por desenvolver o trabalho a partir de dois eixos: o conteúdo da exposição e a acessibilidade cultural.

Sobre o segundo eixo, percebeu-se logo o papel da mediação acessível ${ }^{9}$ como o amálgama entre os demais recursos e como sendo a ação que resolvia dois aspectos muito favoráveis: receptividade e acolhimento.

Nesta proposta, a mediação acessível foi indispensável como catalisador dos recursos disponíveis ao visitante público-alvo do trabalho e elemento de garantia do seu êxito em duas dimensões de acessibilidade: atitudinal e comunicacional. Portanto, a habilidade do mediador foi um investimento diferencial para que o visitante com deficiência tivesse uma experiência multissensorial do conteúdo da exposição. O Memorial do Anglo foi o piloto pelo qual se pautaram os princípios que vieram a ser aplicados na exposição do Museu do Doce.

\section{ENTRE O PATRIMÔNIO MATERIAL E O IMATERIAL: O MUSEU DO DOCE}

A próxima exposição do Programa oferecia um conjunto de desafios muito maior. No entanto, esperava-se que a experiência acumulada viesse a tornar os resultados mais satisfatórios. O local era maior, consistia em praticamente toda a área expositiva de uma antida localizada no centro histórico da cidade de Pelotas, tombada como patrimônio nacional ${ }^{10}$ pelo Instituto do Patrimônio Histórico e Artístico Nacional (IPHAN). Construída entre em 1878 e 1880, em estilo eclético para ser a moradia de uma família de grande poder econômico, político e social da cidade, a Família Antunes Maciel. Atualmente, abriga a sede do Museu do Doce da UFPel, que foi criado através de Portaria do Reitor em 30 de dezembro de 2011. A restauração do prédio foi entregue à comunidade em 2013, junto com a inauguração do museu. A missão do Museu do Doce é salvaguardar os saberes e fazeres da tradição doceira de Pelotas e região.

\footnotetext{
${ }^{8}$ A acessibilidade comunicacional, segundo SASSAKI (2009), é a eliminação de barreiras de comunicação interpessoais, escritas e entre ambientes e seus visitantes.

${ }^{9}$ Constitui-se da tríade: discurso expositivo, visitante e recursos de tecnologia assistiva.

${ }^{10} 1977$.
} 
Rev. Interd. em Cult. e Soc. (RICS), São Luís, v. 7, n. 2, p. 191- 206, jul./dez. 2021 ISSN eletrônico: $2447-6498$

Sendo um museu universitário e profundamente relacionado com a cidade, um fato somou-se para aportar significado ao lugar e ao museu. Entre 2006 e 2008, pesquisadores vinculados ao Laboratório de Ensino e Pesquisa em Antropologia e Arqueologia da UFPel desenvolveram uma pesquisa que acabou por subsidiar o preenchimento do Inventário Nacional de Referências Culturais (INRC)- produção de doces tradicionais pelotenses. Finalizado, o relatório da pesquisa foi apresentado ao Instituto do Patrimônio Histórico e Artístico Nacional (IPHAN) no mesmo ano de 2008 e após um período de dez anos em análise, no dia 15 de maio de 2018, na $88^{\text {a }}$ Reunião do Conselho Consultivo do Patrimônio Cultural, ligado IPHAN, ocorreu o fato inusitado: o julgamento do conjunto histórico do município de Pelotas (RS) e do inventário do doce. Em duas reuniões do conselho, no mesmo dia, o Conjunto Histórico ${ }^{11}$ foi aprovado como Patrimônio Cultural Brasileiro e as "Tradições Doceiras da Região de Pelotas e Antiga Pelotas" foram declaradas patrimônio imaterial do Brasil, passando a ser inscritas no Livro dos Saberes nacional.

A casa na qual se desenvolveu o trabalho é, curiosamente, uma síntese do contexto que determinou a arquitetura eclética da cidade e a construção da tradição doceira. $\mathrm{O}$ atual nome histórico já diz isso: A Casa do Conselheiro. Construída por Francisco Antunes Maciel, que foi conselheiro do Império por um ano, todos os detalhes ornamentais que a distinguem referendam o poder político e econômico da família. A tradição doceira funda-se sobre um dos hábitos alimentares que marcou a vida na cidade, a produção e o consumo de doces de origem portuguesa e, em um segundo momento, de doces feitos pelas famílias de imigrantes na zona rural da cidade. No momento em que a casa foi construída, o poder econômico ainda estava na mão dos proprietários de terras, criadores e charqueadores e, foram eles, a exemplo do bem viver europeu, que implantaram novos modos tais como se fossem do local, inclusive hábitos da mesa: banquetes, chás, saraus. Em todos os eventos, o doce celebrava o hedonismo do poder. A exposição deveria combinar ambas as metas: contar sobre o local e sobre o patrimônio material que lá estava.

Figura 1: Fachada do Museu do Doce

\footnotetext{
11 O conjunto reúne a Chácara da Baronesa (atual sede do Museu da Baronesa), a Charqueada São João (de 1810), o Parque Dom Antônio Zattera e as praças José Bonifácio, Coronel Pedro Osório, Piratinino de Almeida e Cipriano Barcelos.
} 
Rev. Interd. em Cult. e Soc. (RICS), São Luís, v. 7, n. 2, p. 191- 206, jul./dez. 2021

ISSN eletrônico: $2447-6498$

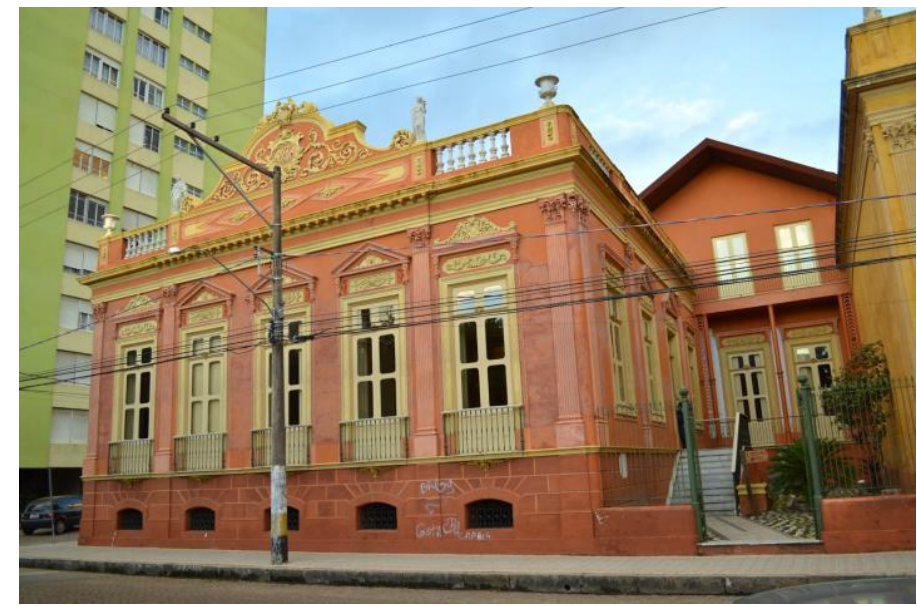

Fonte: Google imagens.

\section{ENTRE O SAL E O AÇÚCAR: O DOCE ATRAVÉS DOS SENTIDOS}

Desse modo, a exposição encontrava-se na intersecção entre uma narrativa da tradição doceira e outra, da própria casa. Através de uma parceria realizada entre o Programa "O Museu do Conhecimento" e a equipe do Museu do Doce, no ano de 2015, começou-se o planejamento desta que seria a primeira exposição de longa duração do museu. Durante o primeiro ano foram feitas visitas teste com os recursos então disponibilizados pelo Museu do Doce e as instituições parceiras do Programa, bem como a formação de ambas as equipes (Museu do Doce e Museu do Conhecimento). Assim, é no ano de 2016 que começam os trabalhos efetivos de proposição de uma exposição acessível.

Seguindo os moldes de formação já utilizados anteriormente, as equipes foram instrumentalizadas nos conceitos basilares do Programa: Desenho Universal ${ }^{12}$ e Acessibilidade em Museu através de oficinas, onde os próprios graduandos, sob coordenação de seus orientadores, apresentavam os conteúdos pontuando suas possibilidades de atuação no desenvolvimento da exposição.

A primeira oficina consistiu em uma visita guiada ao Museu do Doce, para que a equipe conhecesse o local da exposição como o visitante o conheceria.

O segundo momento foi dividir a equipe em grupos de trabalho, que seriam responsáveis por desenvolver as ações referentes aos diferentes recursos que se somariam na exposição. Respeitando um calendário, previamente acordado, os resultados eram

\footnotetext{
12 Segundo a Lei Brasileira de Inclusão (Lei 13.146/2015), o Desenho Universal é concepção de produtos, ambientes, programas e serviços a serem usados por todas as pessoas, sem necessidade de adaptação ou de projeto específico, incluindo os recursos de tecnologia assistiva.
} 
Rev. Interd. em Cult. e Soc. (RICS), São Luís, v. 7, n. 2, p. 191- 206, jul./dez. 2021 ISSN eletrônico: $2447-6498$

apresentados ao grande grupo para serem por esse avaliados e discutidos. Os grupos de trabalho estavam divididos em: Esquemas e maquetes táteis, Novas tecnologias em museus, Sinalização, Programa de Acessibilidade, Mediação Acessível e Audiodescrição.

Uma das principais etapas do processo foi o desenvolvimento do Programa de Acessibilidade, planejado pela primeira autora a partir de uma pesquisa baseada nos recursos de acessibilidade do Museu da Comunidade Concelhia da Batalha (MCCB), em Portugal, e nos resultados positivos encontrados no Memorial do Anglo, da UFPel. O MCCB foi escolhido como modelo pelo seu caráter exemplar e premiado de museu inclusivo. Planejado e desenvolvido desde a sua base, por uma equipe multidisciplinar para ser um museu de e para todos, o MCCB tornou-se uma referência no assunto e tendo a primeira autora realizado um estágio em Acessibilidade Cultural, de doze meses no referido museu, havia ali uma ótima fonte de inspiração para novos projetos.

Com o Programa de Acessibilidade do Museu do Doce concluído e aprovado, partiuse para a confecção dos recursos de acessibilidade positivamente avaliados. Destaca-se que o Museu do Doce ainda não tinha o seu Plano Museológico pronto e que o seu primeiro documento foi o Programa de Acessibilidade.

Sete meses após o início das atividades elencadas anteriormente, no dia 23 de setembro de 2016, a exposição "Entre o Sal e o Açúcar: O doce através dos sentidos" foi inaugurada com os seguintes recursos de acessibilidade: audiodescrição, esquemas e maquetes táteis que apresentam detalhes arquitetônicos significativos da Casa, textos e legendas em braile, textos em inglês e espanhol, cores contrastantes, textos em fontes com tamanho acessível e sem serifa, iluminação direcionada, mobiliário ergonômico acessível, elevador interno, WC adaptado, estacionamento preferencial para pessoa com deficiência e mediação acessível.

É importante ressaltar que embora se tenha desenvolvido um número significativo de recursos, eles não são a totalidade do que estava planejado e postos no Programa de Acessibilidade. Houve impedimentos de ordem orçamentária e cumprimento do cronograma que fizeram com que produtos mais complexos fossem abandonados.

A inauguração da exposição contou com recursos de audiodescrição e tradução para Língua Brasileira de Sinais.

Como uma de suas missões e compromissos, logo nos primeiros meses da exposição, parte da equipe do Museu do Conhecimento, ligada ao grupo de trabalho da mediação 
Rev. Interd. em Cult. e Soc. (RICS), São Luís, v. 7, n. 2, p. 191- 206, jul./dez. 2021 ISSN eletrônico: $2447-6498$

acessível e audiodescrição, em conjunto com a equipe do Museu do Doce, recebeu visitas com grupos de pessoas com deficiência.

Pertencentes à instituição parceira (Escola Especial Louis Braille), o primeiro grupo a visitar a exposição em dezembro de 2016, contou com 30 alunos heterogêneos, com idades diversas e alguns, para além da deficiência visual, tinham outra deficiência associada. Desse modo, cada visita foi organizada de modo estratégico. Na primeira, dado o grande número, o grupo foi dividido e o fluxo da exposição alterado para que, simultaneamente, os sub-grupos pudessem realizar a visita com seus mediadores. Todos os alunos responsáveis pelo acolhimento a este grupo foram instrumentalizados previamente pela equipe do Museu do Conhecimento. Assim, enquanto a mediação do conteúdo da exposição e da condução pelo espaço eram feitas pelos alunos das graduações em Museologia e em Terapia Ocupacional, a mediação das maquetes ficou sob responsabilidade dos graduandos de Arquitetura e Urbanismo.

Antes de dar início à visitação, propriamente dita, o público foi recepcionado no auditório do Museu para apresentação das equipes e organização prática da visita, que durou cerca de duas horas. Este momento permitiu que os visitantes identificassem os mediadores pela voz e houvesse necessário entrosamento com os mesmos. Ao fim, como uma celebração dos sentidos, os visitantes foram conduzidos a uma sala onde foram recepcionados com Doces Tradicionais Pelotenses. Em meio a experiência sensorial do odor e do sabor, também foi conduzida a avaliação qualitativa acerca da exposição, realizada pelos demais alunos que não atuaram como mediadores.

Figura 2: Mediação Acessível no Museu do Doce

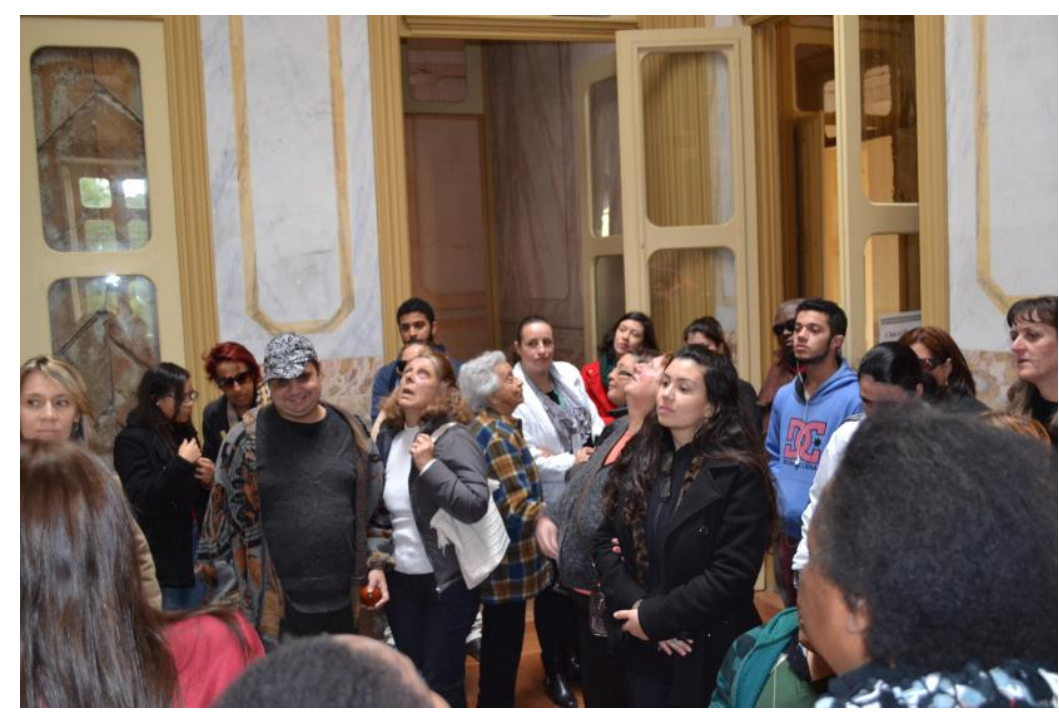

Fonte: Acervo da autora. 
Rev. Interd. em Cult. e Soc. (RICS), São Luís, v. 7, n. 2, p. 191- 206, jul./dez. 2021 ISSN eletrônico: $2447-6498$

O primeiro resultado desta avaliação registrou a satisfação dos visitantes por ter um espaço inclusivo na cidade, com estas características. Este resultado era esperado, sobretudo porque o grupo, formado pela equipe técnica do Centro de Reabilitação Visual, os usuários do Centro e acompanhantes realizou a visita como um evento lúdico. Havia o inusitado, também, de encontrar em um espaço público, recursos elaborados para a condição do público. Pela eficácia comunicacional, as maquetes e recursos táteis foram majoritariamente destacados pelos visitantes. Estas, aliadas à audiodescrição, efetivaram o entendimento dos detalhes arquitetônicos dos tetos do Casarão, tanto para as pessoas com deficiência como para os acompanhantes. Foi destacado, também, o material em braile, que complementou as informações verbais para os que dominavam o sistema de leitura. No entanto, como em outras ocasiões, foram contadas poucas pessoas com domínio deste sistema.

Embora não elencados na avaliação, observou-se que o espaço amplo do interior do museu, as rampas e o elevador foram essenciais para que os visitantes usuários de cadeiras de rodas tivessem o acesso arquitetônico garantido.

A segunda visita a ser relatada ocorreu com um grupo de oito pessoas com deficiência visual, participantes de um evento para cegos que ocorria na cidade e que visitaram o museu em maio de 2017. O grupo foi recebido por duas mediadoras: uma graduanda de Terapia Ocupacional, que os conduziu pelo espaço, explicando e apresentando os recursos de acessibilidade, e outra graduanda da Museologia, responsável pela apresentação do conteúdo da exposição. O grupo, também heterogêneo, era composto por pessoas com cegueira e pessoas com baixa visão, todos com idades diversas.

Diferente do primeiro grupo mencionado acima, estes visitantes eram pessoas mais experientes e críticas no que tange aos ambientes culturais inclusivos e contribuíram destacadamente, avaliando a efetividade dos recursos de acessibilidade comunicacional.

Figura 3: Mediação Acessível no Museu do Doce 


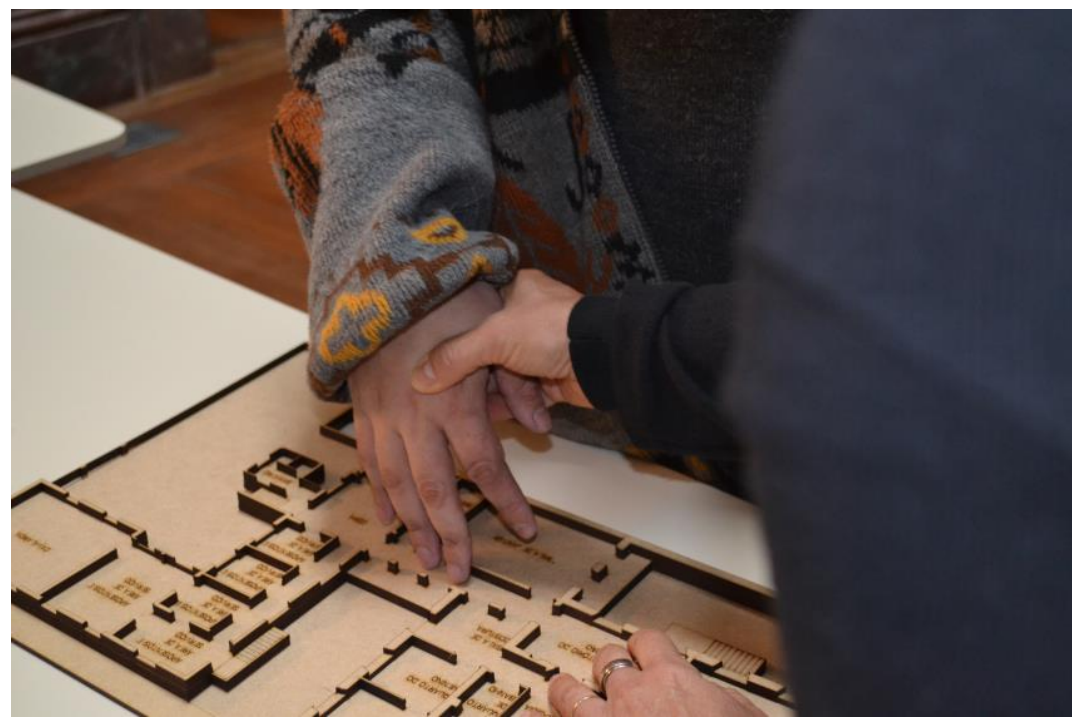

Fonte: Acervo da autora.

\section{CONSIDERAÇÕES FINAIS}

Embora o Programa tenha sido concluído, vários desdobramentos consolidaram os resultados obtidos. O principal, é que o tema acessibilidade em museus vingou. Tornou-se recorrente e corrente, gerando várias outras iniciativas. Na época em que o trabalho se desenvolvia, o Museu da Baronesa, considerado o Museu Municipal da Cidade, foi assistido pela equipe do Gegradi coordenada por uma pesquisadora vinculada ao Programa MCT, que realizou esquemas táteis de exemplares do mobiliário acervo daquele Museu. Parte da equipe levou para a Rádio Federal FM, setor da Comunicação Social da UFPel o programa "Fotografia para ouvir", com audiodescrição de fotografias históricas da Universidade. Os mesmos integrantes desenvolveram o projeto do livro Multiformato da Casa do Conselheiro, que foi aprovado por um produtor cultural em Edital Procultura do Rio Grande do Sul. Encontra-se concluído e em distribuição. A Rede de Museus da UFPel incorporou o trabalho de mediação acessível e a primeira autora deste artigo desenvolveu o Plano de Acessibilidade da Pró-Reitoria de Extensão e Cultura e um ebook sobre Programas de Acessibilidade ${ }^{13}$, que foi publicado por este setor no ano de 2018. Durante os eventos de museus (Semana dos Museus e Primavera dos Museus), desde 2017 estão sendo oferecidas oficinas sensoriais que culminam com uma discussão sobre acessibilidade.

\footnotetext{
${ }^{13}$ Um museu para todos: Manual para programas de acessibilidade. (SALASAR, D. N. 2018)
} 
Rev. Interd. em Cult. e Soc. (RICS), São Luís, v. 7, n. 2, p. 191- 206, jul./dez. 2021

ISSN eletrônico: $2447-6498$

No caso do Museu do Doce, para além dos recursos implementados e atividades sensoriais já citadas neste artigo, a equipe do museu montou um grupo de estudos interdisciplinar, onde a acessibilidade é um tema recorrente nas discussões.

Iniciativas voltadas para maior ou menor público estão sendo feitas, o que leva a refletir sobre a acessibilidade cultural como um campo essencialmente interdisciplinar, que enquanto demanda a ampliação da condição de acesso para a possibilidade de exercício da cidadania cultural, naturaliza o convívio entre pessoas com e sem deficiência. Entendida como uma política pública para fruição nos mais diversos contextos onde a cultura está inserida, "a acessibilidade cultural é uma conquista adquirida apartir de diferentes leis e decretos nacionais e internacionais" (DORNELES; JUNIOR, 2014, p. 107) mas, é também, uma conquista de um conceito de deficiência contemporâneo, fundado sobre a aceitação da diferença.

Reforçou-se o entendimento de que os museus são, potencialmente, um canal de comunicação dirigido a muitos públicos e no caso em questão, a exposição consistiu no núcleo de um processo de integração entre os visitantes. Os resultados aqui apresentados articulam vários princípios como a universalidade do acesso aos museus, os direitos das pessoas com deficiência e, principalmente a relevância do papel da Universidade pública frente as suas ações de aproximação com a comunidade através da extensão universitária.

Planejar, desenvolver e executar uma exposição inclusiva é necessariamente tarefa para uma equipe interdisciplinar, seja pelo fato de que os conhecimentos devem dar conta de campos específicos e amplos: cultura, acessibilidade, museus, públicos, recursos assistivos, métodos expositivos etc., seja pelo resultado que se espera: o fato narrativo, coerente e convergente. Sendo assim, o trabalho não é uma lista de necessidades a serem contempladas por especialistas específicos, mas o corpo único que consiste em uma exposição com o seu conteúdo apresentado de modo universal, sob o princípio do uso simples e intuitivo, de recursos equitativos, da disponibilização da informação de modo perceptível, da tolerância e da generosa disposição que mais oferece do que demanda.

Ao fim, o esforço feito expressou o desejo de que a exposição "Entre o sal e o açúcar: o doce através dos sentidos" atingisse o resultado de inclusão do maior número de pessoas possível, tenham elas deficiência ou não. O grupo queria que ver, ouvir, tocar e sentir fosse uma experiência de compartilhamento e compreensão dos modos do conhecimento que cada um pode ter sobre um mesmo objeto, em um mesmo local, e que, através dessa compreensão, 
Rev. Interd. em Cult. e Soc. (RICS), São Luís, v. 7, n. 2, p. 191- 206, jul./dez. 2021 ISSN eletrônico: $2447-6498$

nos fizéssemos mais próximos uns dos outros, mais gentis, mais inclusivos. Que o conseguido alimente as expectativas pelo que poderá, ainda, ser esperado.

A melhor conclusão foi a de que o Museu do Doce se apresentou como um grande laboratório, onde os alunos e profissionais tiveram a oportunidade de testar a confluência dos seus conhecimentos com os saberes dos parceiros. Não se partia de certezas nem se chegava a modelos conclusivos. Tudo foi, desde o início, uma grande experiência que abriu portas para outras possibilidades e caminhos. Caminhos que levam a mais caminhos, porque um museu que deseja ser para todos não conclui o seu trabalho, apenas avança. Por fim, neste espaço, constituiu-se a primeira experiência intencionalmente acessível no e para o campo cultural da cidade de Pelotas.

\section{REFERÊNCIAS}

ASSOCIAÇÃO BRASILEIRA DE NORMAS TÉCNICAS. NBR 9050: acessibilidade a edificações, mobiliário, espaços e equipamentos urbanos. Rio de Janeiro: ABNT, 2015.

BAUMAN, Zygmunt. Modernidade e ambivalência. Pós-modernidade ou vivendo com a ambivalência. Rio de Janeiro: Jorge Zahar Ed. 1999.

BRASIL. Lei 13.146. Lei Brasileira de Inclusão - Estatuto da Pessoa com Deficiência. Disponível em: <http://www.planalto.gov.br/ccivil_03/_Ato20152018/2015/Lei/L13146.htm>. Acesso em: 20/02/2019

DORNELES, Patricia; ALBERTACCI JUNIOR, Geraldo. Rede de articulação, fomento e formação: $\mathrm{O}$ curso de especialização como instrumento da política e acessibilidade cultural para pessoas com deficiência. In: CARDOSO, Eduardo; CUTY, Jenifer (Orgs.).

Acessibilidade em ambientes culturais: relatos de experiências. Porto Alegre: Marcavisual, 2014. p.102-120.

SALASAR, Desirée Nobre. Um museu para todos: Manual para programas de acessibilidade. Pelotas: Ed. da UFPel, 2019.

SANTOS, Boaventura de Sousa. Democratizar a democracia: os caminhos da democracia participativa. Rio de Janeiro: Civilização Brasileira, 2002.

SASSAKI, Romeu Kazumi. Inclusão: acessibilidade no lazer, trabalho e educação. Revista Nacional de Reabilitação (Reação). São Paulo, v. 12, p. 10 -16, mar./abr. 2009. 